\title{
Past, present, and future perspectives of telemedical assistance at sea: a systematic review
}

\author{
Getu Gamo Sagaro ${ }^{1}$, Francesco Amenta ${ }^{1,2}$ \\ ${ }^{1}$ Telemedicine and Telepharmacy Centre, School of Medicinal and Health Products Sciences, University of Camerino, Italy \\ ${ }^{2}$ Research Department, International Radio Medical Centre (CIRM), Rome, Italy
}

\begin{abstract}
Background: Telemedicine is an effective technology for evaluating, diagnosing, treating, and providing health care services for remote populations, including seafarers, in case of diseases or accidents on board. Delivery of telemedicine in a maritime environment is not an easy task and, in general, differs from what can be done onshore. The aim of this review is to provides an overview of Telemedical Maritime Assistance Services (TMAS) in Europe by describing the previous and current status in terms of communication technologies as well as the nature of services rendered at sea. Secondly, to discuss the areas needing improvement and future directions to improve the quality of offshore telemedicine services.

Materials and methods: Different databases, including PubMed (Medline), Google Scholar, Scopus, and journal of International Maritime Health, were searched between August 1 and September 15, 2019. Articles only published from 1969 to 2019 were considered. Relevant articles were selected by reviewing keywords, titles, and abstracts initially based on our inclusion and exclusion criteria. We critically reviewed the full-text articles included in this review. Information on the means of communication, telemedicine services, years of publication, and the name of the first author was extracted from selected studies. The quality of the selected studies was assessed using the criteria of the Newcastle-Ottawa scale.

Results: Initially, 135 articles were identified through searching various databases by using keywords, abstracts, and titles. After removing the duplicates, 121 articles remained. Then we performed an independent article assessment and selection based on the selection criteria, which removed an additional 61 studies, leaving 60 papers. Finally, 27 full-text papers left, and we critically reviewed it. In 27 accepted articles, email and telephone were used most often and accounted for $30 \%(17 / 57)$ and $28 \%(16 / 57)$ of all communication links, respectively. Teleconsultation was the most used telemedicine service on board and represented $58.6 \%(17 / 29)$ of accepted papers.

Conclusions: Email and telephone were the principal means of TMAS doctors to provide medical advice as well as assistance for patients at sea. Despite the potential offered by technological progress, there are still many limitations to the provision of adequate medical care at sea. The modernisation of telemedicine services will help decrease the gap in healthcare delivery at sea.
\end{abstract}

(Int Marit Health 2020; 71, 2: 97-104)

Key words: telemedicine, telemedical maritime assistance service, medical advice, seafarers, teleconsultation, telemonitoring, telemedicine services

\section{INTRODUCTION}

Shipping is one of the most widespread transportation systems, and more than $80 \%$ of the world's trade utilises it [1, 2]. Approximately 65,000 deep-sea merchant ships operate worldwide, carrying nearly 1.6 million sailing seafarers [3, 4]. In general, the workforce's on board ships are grouped into three main categories, deck, engine, and galley/support personnel. Deck and engine groups include officers and ratings [5]. Globally, the number of seafarers actively employed on board ships in 2015 included 774,000 officers and 873,500 ratings [3]. 
In Europe, the maritime industry plays a significant role by connecting more than $70 \%$ of the European market with its external trade partners as well as $36 \%$ of intra-European union trade exchange [6]. Nearly $32 \%$ of the world's total merchant fleet with more than 300 main seaports along its coastline managed by European Union (EU) [6]. Besides, approximately 400 million passengers are traveling per year at EU seaports. Regarding maritime health, given their particularly hazardous work environment [2], marked by physical and psychological strain, sudden climate change, and unexpected electromagnetic, vibration, and sound radiation [7], workers at sea, have higher rates of mortality, injuries, and illnesses compared with workers ashore, with a probability of one in eleven of being injured on the job [7].

For most of maritime history, except for rare exceptions when a doctor was on board, healthcare on board merchant ships was in the hands of the captain, whose training may have included rudimental notions of hygiene and medicine. Following the development of radio in the 1920s, doctors had the means to evaluate, diagnose, treat, and provide medical advice for sick or wounded seafarers as well as passengers. Different EU countries $[8,9]$ set up a radio medical centre 80 years ago to prove medical advice at sea. However, there are still various limitations to providing appropriate medical care on board due to incomplete medical data, poor still images, absence of trained paramedics, and poor radio communication coverage $[10,11]$. This should highlight the need to update maritime telemedicine in terms of communication links/networks, medical diagnose, treat, and provide medical advice for sick or wounded seafarers as well as passengers.

Telemedicine in the maritime environment differs from the onshore provision of telehealth services. In general, in case of sudden diseases or injuries on board ships, the chance of receiving proper and effective treatment is not the same for seafarers as for workers on the land, given the inadequate medical skills of ship officers with duties for medical care on board, the limited range of medical equipment and the limited supply of medical products aboard [12, 13].

In general, there are several reviews published on telemedicine services regarding the onshore [14-18]. However, reviews of telemedicine services in the context offshore are scarce [19]. The purpose of this review aimed to provide an overview of Telemedical Maritime Assistance Services (TMAS) in Europe by describing the previous and current status in terms of communication technology as well as the nature of services at sea. Besides, areas needing improvement and future directions to improve the quality of maritime telemedicine services will be discussed.
Table 1. Detail search strings used for the PubMed database

1. "Medical aid" [Title/Abstract] AND "on board" [Title/Abstract]

2. "Offshore" [Title/Abstract] AND "telemedicine" [Title/Abstract]

3. "Medical" [Title/Abstract] AND "assistance" [Title/Abstract]) AND "at sea" [Title/Abstract]

4. "Radio medical" [Title/Abstract]

5. "Maritime" [Title/Abstract] AND "Telemedicine" [Title/Abstract]

6. "Telemedicine" [Title/Abstract] AND "at sea" [Title/Abstract]

7. "Telemedical" [Title/Abstract] AND "assistance" [Title/Abstract]) AND "onboard" [Title/Abstract]

8. "Radio medical" [Title/Abstract] AND "advice" [Title/Abstract]

9. "Maritime" [Title/Abstract] AND "Medicine" [Title/Abstract]

\section{MATERIALS AND METHODS}

\section{SEARCHING STRATEGY}

The different electronic databases, including PubMed (Medline), Google Scholar, Scopus, and the journal of International Maritime Health, were searched to identify the relevant studies. Besides, additional articles were also extracted from the references list of selected papers to get a complete overview of the telemedical maritime assistance services in EU countries. The literature searches were carried out between August 1 and 15 September 2019. We used following key terms for searching in this review: "maritime telemedicine", "Radio Medical advice", "telemedical assistance on board", "telemedicine at sea", "offshore", "maritime medicine", "medical assistance at sea", "maritime health", "medical aid on board". Boolean operators and quotes have been used in the search process to acquire variations in the lexicon and for a better search strategy (Table 1) [20]. A manual search of Google Scholar, Scopus, and the journal of International Maritime Health was performed in web-based resources. Initially, keywords, abstract, and titles were used. Finally, we identified the relevant articles by reviewing full texts for articles independently.

\section{INCLUSION AND EXCLUSION CRITERIA}

Studies expected to describe the means of communication and offshore telemedicine services to be considered in the review. Furthermore, studies eligible for selection included published in peer-reviewed journals between 1969 and 2019 , conducted within the EU countries, and published in English. Whereas: 1) review studies, 2) unpublished documents, 3) studies published only as an abstract, 4) expert opinions were excluded from the review. 


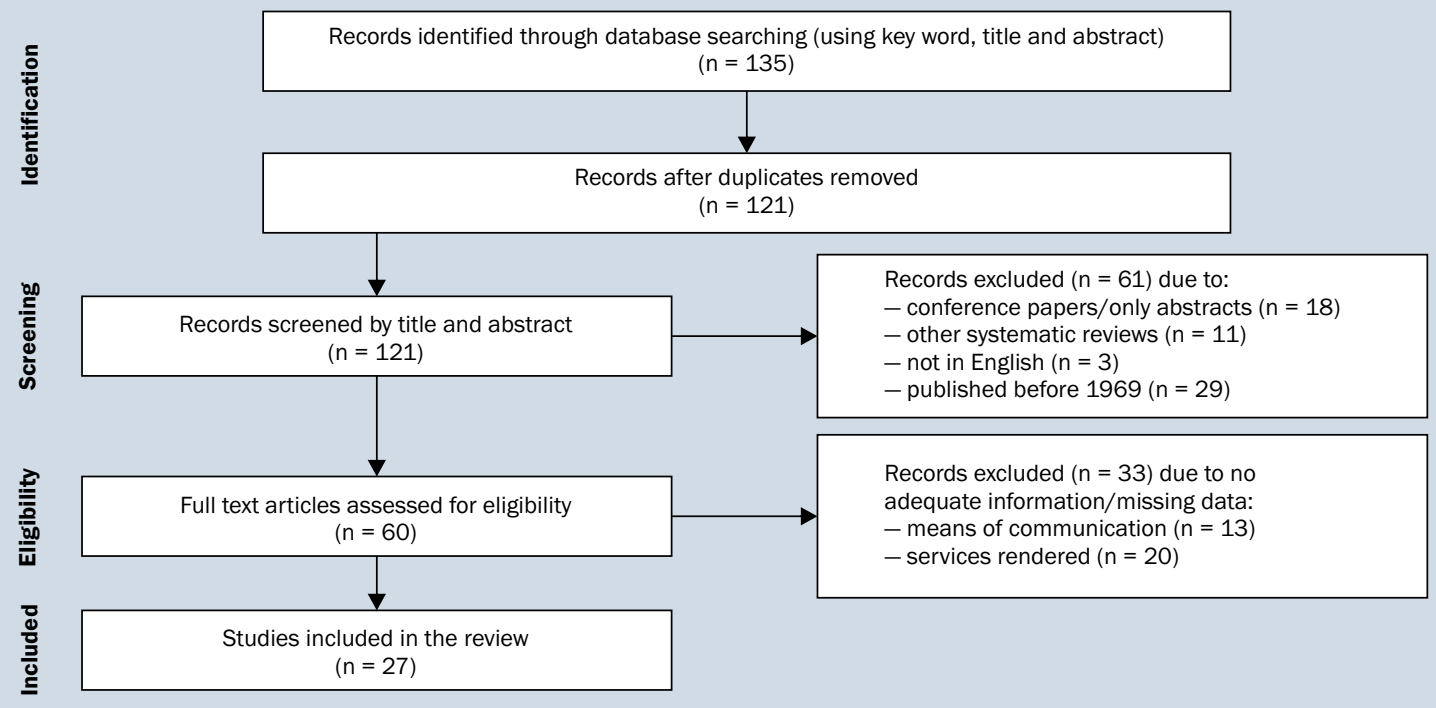

Figure 1. Literature search flow chart with inclusion and exclusion criteria

\section{DATA EXTRACTION AND MANAGEMENT}

The information extracted from the selected literature based on the following defined variables: 1) Means of communication, defined as the means used to facilitate the practice of telemedicine in terms of receiving and transmitting the information. 2) Maritime telemedicine services; this category defines the types of telemedical services provided during the study period, and the other information extracted from the selected articles were: 3 ) the name of the first author, 4) publication year. These variables have been taken into account based on previous studies and literature reviews to assess, analyse, and evaluate the previous and current status of maritime telemedicine services. Data extraction conducted using a Microsoft Excel form that lists all the information mentioned above. The first author G.G.S. has extracted the required information from accepted articles. The second author F.A. has reviewed the completed form and made corrections when necessary.

\section{QUALITY ASSESSMENT}

We used the Newcastle-Ottawa-Scale [21] to evaluate the quality of the selected articles. We assessed each selected study on 8 items and assigned up to a maximum of 9 points in 3 areas, including selection, comparability, and outcomes of interest with detailed analysis. As a result, we evaluated the quality of the selected studies based on agreed category scores ranging from 0 to 9: low quality (0-4), moderate quality (5-6), and high quality (7-9). The assessment of the title and abstracts was performed by two (G.G.S. and F.A.) reviewers independently. If any disagreement about inclusion and exclusion criteria, the full article was assessed. Besides, the disagreement on paper selection was resolved by the discussion between authors. The full paper was retrieved after the approval of reviewers based on the selection criteria, and the entire article assessed again separately.

\section{RESULTS}

\section{RELEVANT ARTICLES}

We identified a total of 135 articles through searching databases by using keywords and titles. The articles were filtered using the publication years from 1969 to 2019 and the inclusion and exclusion criteria. After removing duplicates, 121 papers remained. The authors did an independent assessment of the articles based on inclusion and exclusion criteria. Then after screening titles and abstracts, 61 papers rejected. Besides, full-text papers were assessed, and after evaluation, we excluded 33 full-text length articles. Finally, 27 full-text papers left, and we critically reviewed it (Fig. 1).

\section{MEANS OF COMMUNICATION}

As shown in Table 2, in general, six various means of communication were identified through different literature review during the study period. These include email, telephone, radio, and others (telefax, fax). Accordingly, email was the most used means of communication represented by $30 \%(17 / 57)$. Telephone and radio were the second and third most used means of communication for the transmission of medical information. They accounted for $(28 \%$, 
$16 / 57)$ and $(21 \%, 12 / 57)$ of all communication tools, respectively. Videoconference $(7 \%, 4 / 57)$ was the least used means of communication to transmit and receive medical data during the study period. The other means of communication, such as fax and telefax $(14 \%, 8 / 57)$, were used as

Table 2. Means of communication reported in selected articles from 1969 to 2019

\begin{tabular}{ll}
\hline Means of communication & Frequency (\%) \\
\hline Email & $17(30 \%)$ \\
Telephone & $16(28 \%)$ \\
Radio & $12(21 \%)$ \\
Videoconference & $4(7 \%)$ \\
Others (fax, telefax) & $8(14 \%)$
\end{tabular}

a means of communication for telemedicine services. Table 3 describes all selected studies along with reported means of communication as well as the type of telemedicine services rendered at sea [22-48].

\section{MARITIME TELEMEDICINE SERVICES}

In general, 8 types of maritime telemedical services were identified in accepted articles. These included teleconsultation, telepathology, data sharing, telemonitoring, teledentistry, teledermatology, teletraining, and radio medical advice (Table 4). Of these, teleconsultation is the most used and accounted for $58.6 \%(17 / 29)$ of accepted articles. Data sharing was the second most used telemedicine services on board and accounted for $10.4 \%$ (3/29). Tele pathology, telemonitoring, and radio medical advice were third often provided services on board and accounted for nearly $7 \%$

Table 3. Summary of selected articles with the name of the first author, publication year, means of communication, and nature of services

\begin{tabular}{|c|c|c|c|c|}
\hline Name of the first author & Year & Means of communication & Telemedicine service & Quality score \\
\hline F. Amenta [22] & 1969 & Telephone, telefax, radio & Teleconsultation & 5 \\
\hline N. Rizzo [23] & 1997 & Radio, telefax, telephone, fax & Teleconsultation & 5 \\
\hline G. Anogianakis [24] & 1998 & Videoconference & Teleconsultation & 6 \\
\hline G. Anogianakis [25] & 2000 & Videoconference & Tele education/training & 5 \\
\hline J. Norum [26] & 2002 & Radio, fax, telephone, email & Data sharing & 8 \\
\hline K. Aujla [27] & 2003 & Radio & Radio medical advice & 6 \\
\hline O.C. Jensen [28] & 2005 & Telephone, email, telefax & Teleconsultation & 6 \\
\hline F. Mair [29] & 2008 & Videoconference & Telemonitoring, teleconsultation & 4 \\
\hline K. Webster [30] & 2008 & Email, telephone & Telemonitoring & 7 \\
\hline K. Westlund [31] & 2011 & Email, fax & Teleconsultation & 8 \\
\hline E. Dehours [32] & 2012 & Email, telephone & Data sharing, teleconsultation & 9 \\
\hline L. Grappasonni [33] & 2012 & Telephone, email & Teleconsultation & 7 \\
\hline F. Amenta [34] & 2013 & Email, telephone, telefax, radio & Teleconsultation & 4 \\
\hline E. Dahl [35] & 2014 & Email & Teledermatology & 4 \\
\hline M. Kurlapski [36] & 2014 & Radio & Teleconsultation & 7 \\
\hline E. Dehours [37] & 2016 & Telephone, email & Telepathology & 6 \\
\hline S. S. Mahdi [38] & 2016 & Email & Data sharing & 9 \\
\hline S. S. Mahdi [39] & 2016 & Email, telephone, radio & Teleconsultation & 7 \\
\hline K. Westlund [40] & 2016 & Telephone, fax, email, radio & Teleconsultation & 8 \\
\hline E. Dehours [41] & 2017 & Telephone, email & Telepathology & 6 \\
\hline C. Marimoutou [42] & 2017 & Telephone, email & Teleconsultation & 9 \\
\hline T.-E. Holt [43] & 2017 & Telephone & Teleconsultation & 7 \\
\hline C. Montocchio-Buadès [44] & 2018 & Radio & Teleconsultation & 7 \\
\hline K. Herttua [45] & 2019 & Radio & Teleconsultation & 9 \\
\hline J. Szafran-Dobrowolska [46] & 2019 & Email, telephone & Teleconsultation & 6 \\
\hline R. Mulić [47] & 2019 & Email, telephone, video, radio & Radio medical advice & 6 \\
\hline P. Binaisse [48] & 2019 & Radio, email & Tele dentistry & 8 \\
\hline
\end{tabular}


Table 4. Maritime telemedicine services reported in selected articles from 1969 to 2019

\begin{tabular}{ll}
\hline Telemedicine services & Frequency (\%) \\
\hline Teleconsultation & $17(58.6 \%)$ \\
Data sharing & $3(10.4 \%)$ \\
Telepathology & $2(6.7 \%)$ \\
Radio medical advice & $2(6.7 \%)$ \\
Telemonitoring & $2(6.7 \%)$ \\
Teledermatology & $1(3.5 \%)$ \\
Teledentistry & $1(3.5 \%)$ \\
Tele-education/training & $1(3.5 \%)$
\end{tabular}

in the equal rank of accepted studies. Teledermatology, teledentistry, and teletraining were used almost $4 \%$ of accepted articles, respectively. Telemedicine services are used most of the time in the context of accidents or emergencies on board.

\section{DISCUSSION}

This study provides an overview of telemedical assistance at sea, focusing on means of communication and the nature of the medical services offered on board from 1969 to 2019. Therefore, in order to provide important answers to questions about the growth of telemedicine at sea, considering communication technologies and the nature of on board services are vital aspects. Access to telemedicine services at sea is limited compared to onshore telemedicine. Offshore operating locations are challenging for delivering emergency medical care to personnel due to inadequate coverage of communication networks, bad weather conditions, absence of health professionals, or trained paramedics on board. However, regardless of these limitations, for the last 50 years, telemedicine by use of various means of communication such as telephone $[22,23,26,28,30$, $32-34,37,39-43,46,47]$, radio [22, 23, 26, 27, 34, 36, $39,40,44,45,47,48]$, videoconference [24, 25, 29, 47], email [26, 28, 30-35, 37-42, 46-48], and telefax [22, $23,28,34]$ has been offered different emergency medical services at sea successfully. As a result, telemedicine in the maritime industry has made it possible to reduce number of unnecessary evacuations (nearly by $20 \%$ per year), reduce treatment delay, improve the perception of safety, and increase patient satisfaction [29, 32, 49, 50].

In this review, the email and telephone were used to be the principal means for onshore physicians to provide medical advice as well as to share medical data for patients at sea. The early form of telemedicine involved communication over radio and telephone $[51,52]$, but the telephone remains a major communication tool between onshore and offshore for medical advice. Historically, in the $19^{\text {th }}$ century, most merchant ships had no medical personnel aboard, lacked areas dedicated to medical or nursing service, and had inadequate levels of hygiene. As it was impossible to communicate with doctors onshore, responsibility for treating diseases or injuries fell to the captain. After the Italian inventor, Guglielmo Marconi, developed radiotelegraphy in 1897 [53], coastal radio centres were established. From the 1920s onwards, radiotelephony was used to provide medical advice for patients on merchant ships [54]. Over the years, there were improvements in the range of radiotelephony services. After World War II, it became widespread and further improved ship to shore communications [55]. The first license for a radio medical service was issued on November 18, 1920, to the Seamen's Church Institute of New York. Then, many EU countries have got a radio medical license. As a result, Sweden in 1922, the Netherlands in 1930, Germany in 1931, Italy in 1935, Yugoslavia in 1938, Norway in 1949, Spain in 1964, France in 1983, Greece in 1985, Denmark in 1992 [34, 55, 56]. Now that such medical assistance is also provided through satellite-based telecommunication systems, perhaps it would be more precise to adopt the term telemedicine, which in the strict sense indicates the provision of health care services, clinical information, and education over a distance using telecommunication technologies. However, both systems are telecommunication technologies, and therefore we cannot object if the approach with which we assist patients' on board ships today is the same as that used 100 years ago.

Currently, all TMAS centres in Europe use various means of communication such as telephone, telefax, radio, email via satellite (INMARSAT) or other connection links to provide telemedicine services in case of need aboard merchant ships [34, 57-59]. However, direct electronic communication (videoconferencing) between patient and doctor is scarce. To modernise the telecommunication part and to minimise treatment delay and misdiagnosis, as well as to counter the psychological distress caused by the sense of isolation far out at sea, real-time videoconference consultation should also be considered. The outlays needed to purchase advanced telemedicine devices for ships will be more than offset by the increased health and productivity of maritime workers, and of course, the importance of saving lives on board. Furthermore, the use of TMAS offers significant savings to the industry or shipowners (approximately $€ 150$ million per year) [50]. Today, satellite technology has made medical services available at sea with high accuracy. In keeping with this change, radio medical centres are now called Telemedical Maritime Assistance Service (TMAS) centres. According to the International Labour Organisation (ILO) Convention 2006 and the International Maritime Organisation (IMO) 2006, all maritime nations must have a centre 
that provides medical services for seafarers 24 hours a day [60]. These nations have complied, but with different approaches: Italy and Spain have organisations specifically dedicated to providing telemedicine services, and other countries like Denmark, France, Germany, Norway, and Sweden designate doctors employed in hospital units to provide this service.

This review found that teleconsultation was the most used telemedicine services on board. Most of TMAS centres in Europe staffed seven days a week, 24 hours a day, and $365 / 366$ days a year in which doctors experienced in managing teleconsultations in the context of accidents or emergencies are available for medical advice to on board ships. In addition to providing advice, the doctors may recommend medical evacuation (MEDEVAC) or that the ship changes direction so the patient can be brought to shore [53]. However, improvements in on-board medical and communications equipment and the medical training of crew should be encouraged for advanced teleconsultation service at sea.

The presented study revealed that telemonitoring was one of the least used services on board. It is to be argued that ships will begin to carry telemedical devices capable of transmitting the biomedical data of patients to a TMAS. For example, a telemonitoring device such as blood pressure measuring devices, spirometers, blood glucose level testing kits, Electrocardiogram (ECG) machines or digital thermometers equipped with cables or Wi-Fi connections so that the information can be downloaded to a phone or computer, and from there sent to the doctor. Such systems could even be supported by advanced artificial intelligence. This would make it possible for an inexpert ship crewmember to incorporate objective and accurate biomedical data into his description of the patient's symptoms to the TMAS doctor. Also, early detection of patients with chronic diseases can be of real help in optimising the patient management process and possible prognosis, primarily by preventing an emergency. Because some chronic diseases, particularly cardiovascular diseases, are the leading cause of mortality and morbidity among seafarers [33, 59, 61-63]. It would be useful to have onboard automated external defibrillators in addition to ECG machines.

Similarly, monitoring patients with chronic diseases is key to optimising patient outcomes, and that is certainly not possible without telemonitoring devices on board. Of course, crew members will need training on how to provide necessary life-saving measures in a medical emergency and how to operate the equipment such as ECG, ultrasound, and X-ray and how to transmit the records to TMAS doctors onshore for interpretation. Doctors ashore should also be informed about the new scenario of ships provided with telemedicine equipment because many are specialists in their fields and unfamiliar, even uncomfortable, in managing situations beyond their competence.

In 2006, the ILO had adopted the Maritime Labour Convention (MLC) 2006 [64], and was entered in to force on August 20, 2013. The EU has also paid attention to guarantee the effectiveness of the MLC 2006 to strengthen international regulations within ever more effective community code [65]. Furthermore, EU member states have been encouraged to ratify the Consolidated MLC 2006 [66]. In Chapter 4 (Title 4), the Convention 2006 addresses health protection and medical care on board ship aspects such as training of personnel, the necessity of medicines, equipment, medical data sharing, and means of communication, availability of doctors [60]. Furthermore, the Convention mentions that all seafarers must be covered by adequate measures for the protection of their health and must have access to prompt and appropriate medical care when working on board [60]. Accordingly, today's regulates more than $90 \%$ of the world's gross tonnage fleet [64]. However, it has not yet been fully applied related to health protection and medical care $[65,67,68]$. There are limitations related to patient monitoring, medical data sharing, decision making, and personnel training [67]. This could be explained by the fact that most communication technologies were limited to voice (telephone and radio) and text (email) rather than videoconferencing. Thus, quality of communication, doctor's direct contact with a patient, real-time video calls may be questionable. Consequently, improvement of telemedicine practices through MLC 2006 in terms of improving access to medical data, to have direct contact of TMAS doctors with the patient, development of real-time teleconsultation by satellite or other digital technology connection could improve the quality of services. Also, it would increase to alleviate the concerns of patients and doctors.

\section{CONCLUSIONS}

This review considered only published articles, and there may be many other unpublished projects that have not been reported in this study. The email was the most used means of communication. Teleconsultation has frequently used telemedicine services on board. On the other side, teledermatology, teletraining, telemonitoring, and teledentistry were the least used services on board. Delayed treatment, misdiagnosis, poor patient satisfaction, incomplete patient records, poor image quality undoubtedly limits the quality of medical care at sea. In this regard, the use of real video calls, the installation of telemonitoring devices, and the training of crew members in the applications of telemonitoring devices could help to improve the quality of offshore telemedicine services. In this study, we have demonstrated an overview of various means of communication and telemedicine services at sea. These may benefit decision-makers anticipating the 
improvement of telemedicine practice on board ships. Also, we recommend further research on the overview of the communication technologies and medical applications to confirm these results forming a base for improvement telemedicine services at sea.

\section{REFERENCES}

1. IMO (International Maritime Organization). https://business.un.org/ en/entities/13 (Accessed October 12, 2019).

2. Center for Maritime Safety and Health Studies. Published online 2019. https://www.cdc.gov/niosh/programs/cmshs/port_operations.html (Accessed October 12, 2019).

3. BIMCO, ICS. http://www.ics-shipping.org/docs/default-source/resources/safety-security-and-operations/manpower-report-2015-executive-summary.pdf?sfvrsn=16.

4. Telemedicine: revolutionising healthcare for seafarers. Accessed August 10, 2019. https://www.ship-technology.com/features/featuretelemedicine-revolutionising-healthcare-for-seafarers-5673476/ (Accessed August 10, 2019).

5. Lefkowitz RY, Slade MD, Redlich CA. Injury, illness, and disability risk in American seafarers. Am J Ind Med. 2018; 61(2): 120-129, doi: 10.1002/ajim.22802, indexed in Pubmed: 29250811.

6. European Commission. Maritime Year in Action. Marit Transp. Published online 2018. https://ec.europa.eu/transport/sites/ transport/files/2018-maritime-year-brochure.pdf.

7. Mulić R, Pero V. Comparative analysis of medical assistance to seafarers in the world and the republic of Croatia. 15th Int Conf Transp Sci. Published online. 2012: 1-8.

8. Wenden AL. Handbook of Mautical Medicine. Vol. 3. 1981.

9. Flesche C, Jalowy A, Inselmann G. Telemedizin in der Hochseeschifffahrt? Hightech aus Tradition. Medizinische Klinik. 2004; 99(3): 163-168, doi: 10.1007/s00063-004-1026-5.

10. Bekkadal F. Novel maritime communications technologies. Marine Navigation and Safety of Sea Transportation. 2010, doi: 10.1201/9780203869345.ch55.

11. Technologies NEW. Maritime technology challenges 2030 safer, smarter and greener for a sustainable European maritime sector maritime technology challenges 2030 a vision for European maritime rdi 2030

12. Horneland AM. Maritime telemedicine - where to go and what to do. Int Marit Health. 2009; 60(1-2): 36-39, indexed in Pubmed: 20205126.

13. Jerončić I, Joško N. Maritime Medicine and Medicine for Seafarers. 6th IMSC 2014, B Abstr 1847. Published online. 2014: 1-5.

14. Benger J. A review of telemedicine in accident and emergency: the story so far. J Accid Emerg Med. 2000; 17(3): 157-164, doi: 10.1136/emj.17.3.157, indexed in Pubmed: 10819375.

15. Amadi-Obi A, Gilligan P, Owens N, et al. Telemedicine in pre-hospital care: a review of telemedicine applications in the pre-hospital environment. Int J Emerg Med. 2014; 7: 29, doi: 10.1186/s12245014-0029-0, indexed in Pubmed: 25635190.

16. Keane MG. A review of the role of telemedicine in the accident and emergency department. J Telemed Telecare. 2009; 15(3): 132-134, doi: 10.1258/jtt.2009.003008, indexed in Pubmed: 19364895.

17. Ward MM, Jaana M, Natafgi N. Systematic review of telemedicine applications in emergency rooms. Int J Med Inform. 2015; 84(9): 601-616, doi: 10.1016/j.jimedinf.2015.05.009, indexed in Pubmed: 26072326.

18. Deldar K, Bahaadinbeigy K, Tara SM. Teleconsultation and Clinical Decision Making: a Systematic Review. Acta Inform Med. 2016;
24(4): 286-292, doi: 10.5455/aim.2016.24.286-292, indexed in Pubmed: 27708494.

19. Woldaregay AZ, Walderhaug S, Hartvigsen G. Telemedicine Services for the Arctic: A Systematic Review. JMIR Med Inform. 2017; 5(2): e16, doi: 10.2196/medinform.6323, indexed in Pubmed: 28659257.

20. Collin SMH, Greasby L, Greene T. Boolean Algebra and Its Applications :Dictionary of Information Technology. Peter Collin. 2010.

21. Wells GA, Shea B, O'Connell D, Peterson J, Welch V, Losos PT. The Newcastle-Ottawa Scale (NOS) for assessing the quality of nonrandomised studies in meta-analyses. http://www.ohri.ca/programs/ clinical_epidemiology/oxford.htm (Accessed June 4, 2020).

22. Amenta F, Dauri A, Rizzo N. Organization and activities of the International Radio Medical Centre (CIRM). J Telemed Telecare. 1996; 2(3): 125-131, doi: 10.1258/1357633961929907, indexed in Pubmed: 9375045.

23. Rizzo N, Fulvio S, Camerucci S, et al. Telemedicine for airline passengers, seafarers and islanders. J Telemedicine Telecare. 2016; 3(1_suppl): 7-9, doi: 10.1258/1357633971930562.

24. Anogianakis G, Maglavera S, Pomportsis A, et al. Medical emergency aid through telematics: design, implementation guidelines and analysis of user requirements for the MERMAID project. Int J Med Inform. 1998; 52(1-3): 93-103, doi: 10.1016/s1386-5056(98)00128-2, indexed in Pubmed: 9848406.

25. Anogianakis G. Utilising multimedia for training merchant mariners as paramedics. Stud Heal Technol Inf. 2000; 72: 66-72, doi: 10.3233/978-1-60750-916-5-66.

26. Norum J, Moksness SG, Larsen E. A Norwegian study of seafarers' and rescuers' recommendations for maritime telemedicine services. J Telemed Telecare. 2002; 8(5): 264-269, doi: 10.1177/1357633X0200800504, indexed in Pubmed: 12396854.

27. Aujla K, Nag R, Ferguson J, et al. Rationalizing radio medical advice for maritime emergencies. J Telemedicine Telecare. 2016; 9(1_suppl): 12-14, doi: 10.1258/135763303322196178.

28. Jensen OC, Bo Bøggild N, Kristensen S. Telemedical advice to long-distance passenger ferries. J Travel Med. 2005; 12(5): 254-260, doi: 10.2310/7060.2005.12503, indexed in Pubmed: 16256048.

29. Mair F, Fraser S, Ferguson J, et al. Telemedicine via satellite to support offshore oil platforms. J Telemed Telecare. 2008; 14(3): 129-131, doi: 10.1258/jtt.2008.003008, indexed in Pubmed: 18430278.

30. Webster K, Fraser S, Mair F, et al. A low-cost decision support network for electrocardiograph transmission from oil rigs in the North Sea. J Telemed Telecare. 2008; 14(3): 162-164, doi: 10.1258/ jtt.2008.003021, indexed in Pubmed: 18430291.

31. Westlund K. Infections onboard ship-analysis of 1290 advice calls to the Radio Medical (RM) doctor in Sweden. Results from 1997, 2002, 2007, and 2009. Int Marit Health. 2011; 62(3): 191-195, indexed in Pubmed: 22258846.

32. Dehours E, Vallé B, Bounes V, et al. User satisfaction with maritime telemedicine. J Telemed Telecare. 2012; 18(4): 189-192, doi: 10.1258/jtt.2012.110910, indexed in Pubmed: 22604271.

33. Grappasonni I, Petrelli F, Amenta F. Deaths on board ships assisted by the Centro Internazionale Radio Medico in the last 25 years. Travel Med Infect Dis. 2012; 10(4): 186-191, doi: 10.1016/ j.tmaid.2012.06.006, indexed in Pubmed: 22819258.

34. Amenta F, Capone L, Sibilio F. Telemedical Assistance of Patients on Board Ships Activity of Centro Internazionale Radio Medico (CIRM), the Italian Telemedical Maritime Assistance Service (TMAS). Published online. 2013. 
35. Dahl E. Briefing notes on maritime teledermatology. Int Marit Health. 2014; 65(2): 61-64, doi: 10.5603/IMH.2014.0014, indexed in Pubmed: 25231327.

36. Kurlapski M, Wójcik-Stasiak M, Klincewicz P, et al. TMAS - Maritime Telemedical Assistance Service at the University Centre of Maritime and Tropical Medicine in Gdynia. The first year activity report. Int Marit Health. 2014; 65(3): 174, doi: 10.5603/IMH.2014.0033, indexed in Pubmed: 25471168.

37. Dehours E, Tourneret ML, Roux P, et al. Benefits of photograph transmission for trauma management in isolated areas: cases from the French tele-medical assistance service. Int Marit Health. 2016; 67(2): 83-87, doi: 10.5603/IMH.2016.0017, indexed in Pubmed: 27364173.

38. Mahdi SS, Sibilio F, Amenta F. Dental hygiene habits and oral health status of seafarers. Int Marit Health. 2016; 67(1): 9-13, doi: 10.5603/IMH.2016.0003, indexed in Pubmed: 27029923.

39. Mahdi SS, Amenta F. Eighty years of CIRM. A journey of commitment and dedication in providing maritime medical assistance. Int Marit Health. 2016; 67(4): 187-195, doi: 10.5603/IMH.2016.0036, indexed in Pubmed: 28009394.

40. Westlund K, Attvall S, Nilsson R, et al. Telemedical Maritime Assistance Service (TMAS) to Swedish merchant and passengers ships 1997-2012. Int Marit Health. 2016; 67(1): 24-30, doi: 10.5603/ IMH.2016.0006, indexed in Pubmed: 27029926.

41. Dehours E, Saccavini A, Roucolle $P$, et al. Added value of sending photograph in diagnosing a medical disease declared at sea: experience of the French Tele-Medical Assistance Service. Int Marit Health. 2017; 68(2): 122-125, doi: 10.5603/IMH.2017.0022, indexed in Pubmed: 28660616.

42. Marimoutou $\mathrm{C}$, Tufo $\mathrm{D}$, Chaudet $\mathrm{H}$, et al. Infection burden among medical events onboard cargo ships: a four-year study. J Travel Med. 2017; 24(3), doi: 10.1093/jtm/tax010, indexed in Pubmed: 28355619 .

43. Holt TE, Tveten A, Dahl E. Medical emergencies on large passenger ships without doctors: the Oslo-Kiel-Oslo ferry experience. Int Marit Health. 2017; 68(3): 153-158, doi: 10.5603/IMH.2017.0027, indexed in Pubmed: 28952660.

44. Montocchio-Buadès C, Daurat M, Ducombs M, et al. Management of a polytrauma in the maritime environment. Int Marit Health. 2018; 69(2): 126-128, doi: 10.5603/IMH.2018.0018, indexed in Pubmed: 29939389.

45. Herttua K, Gerdøe-Kristensen S, Vork JC, et al. Age and nationality in relation to injuries at sea among officers and non-officers: a study based on contacts from ships to Telemedical Assistance Service in Denmark. BMJ Open. 2019; 9(12): e034502, doi: 10.1136/ bmjopen-2019-034502, indexed in Pubmed: 31843856.

46. Szafran-Dobrowolska J, Renke M, Wołyniec W. Telemedical Maritime Assistance Service at the University Center of Maritime and Tropical Medicine in Gdynia. The analysis of 6 years of activity. Med Pr. 2020; 71(2): 121-125, doi: 10.13075/mp.5893.00897, indexed in Pubmed: 31929519.

47. Mulić R, Sumić D. Request for professional medical aid on board ocean-going ships in the Republic of Croatia. Int Marit Health. 2019; 70(1): 42-46, doi: 10.5603/IMH.2019.0006, indexed in Pubmed: 30931516.

48. Binaisse $\mathrm{P}$, Dehours E, Bodéré $\mathrm{C}$, et al. Dental emergencies at sea: A study in the French maritime TeleMedical Assistance Service. J Telemed Telecare. 2019 [Epub ahead of print]: 1357633X18818736, doi: 10.1177/1357633X18818736, indexed in Pubmed: 30646814

49. Anscombe DL. Healthcare delivery for oil rig workers: telemedicine plays a vital role. Telemed J E Health. 2010; 16(6): 659-663, doi: 10.1089/tmj.2010.9957, indexed in Pubmed: 20690836.
50. Henny $\mathrm{C}$, Hartington $\mathrm{K}$, Scott $\mathrm{S}$, et al. The business case for telemedicine. Int Marit Health. 2013; 64(3): 129-135, indexed in Pubmed: 24072539

51. MichaelsE. Telemedicine: The best is yet to come, experts say Main enemy of telemedicine may be doctors' reluctance to use it. 1989;141:612-614.

52. Dragos Panait DMF. Tele-cardiology in Remote 0 \& G premises. 2013; 63(April): 16-18.

53. Ricci G, Pirillo I, Rinuncini C, et al. Medical assistance at the sea: legal and medico-legal problems. Int Marit Health. 2014; 65(4): 205-209, doi: 10.5603/IMH.2014.0039, indexed in Pubmed: 25522704.

54. The Evolution of Telehealth: Where Have We Been and Where Are We Going? | The Role of Telehealth in an Evolving Health Care Environment: Workshop Summary | The National Academies Press. https:// www.nap.edu/read/13466/chapter/4 (Accessed October 19, 2019).

55. History. http://www.ncmm.no/about-radio-medico-norway/history (Accessed October 6, 2019).

56. Çakır E, Arslan Ö. Turkish Telemedical Assistance Service: last four years of activity. Int Marit Health. 2018; 69(3): 184-191, doi: 10.5603/IMH.2018.0030, indexed in Pubmed: 30270420.

57. Westlund K, Attvall S, Nilsson R, et al. Telemedical Maritime Assistance Service (TMAS) to Swedish merchant and passengers ships 1997-2012. Int Marit Health. 2016; 67(1): 24-30, doi: 10.5603/ IMH.2016.0006, indexed in Pubmed: 27029926.

58. Vallé $\mathrm{B}$, Bounes $\mathrm{V}$, Dehours $\mathrm{E}$, et al. Use of morbidity and mortality conferences to analyze causes of death at sea: a useful tool in the process of training in maritime medicine. Int Marit Health. 2011; 62(2): 104-109, indexed in Pubmed: 21910113.

59. Jaremin B, Kotulak E, Starnawska M, et al. Causes and Circumstances of Deaths of Polish Seafarers During Sea Voyages. J Travel Med. 1996; 3: 91-95, doi: 10.1111/j.1708-8305.1996.tb00712.x.

60. International Labour Organization. Maritime Labour Convention, 2006, as amended (MLC, 2006). Marit LABOUR Conv 2006, as Amend. https://www.ilo.org/dyn/normlex/en/f.

61. Hansen HL. Surveillance of deaths on board Danish merchant ships, 1986-93: implications for prevention. Occup Environ Med. 1996; 53(4): 269-275, doi: 10.1136/oem.53.4.269, indexed in Pubmed: 8664966.

62. Larsson TJ, Lindquist C. Traumatic fatalities among Swedish seafarers 1984-1988. Saf Sci. 1992; 15: 173-182, doi: 10.1016/09257535(92)90003-I.

63. Roberts SE. Mortality from disease among seafarers in British merchant shipping (1976-1995). Int Marit Health. 2020; 53: 43-58.

64. International Labour Organization. MLC, 2006: What it is and what it does. https://www.ilo.org/global/standards/maritime-labour-convention/what-it-does/lang-en/index.htm (Accessed May 31, 2020).

65. Albertos SR, Palacio AV. Adapting European Legislation to the Maritime Labour Convention 2006 Regulations in Relation to the State Responsibilities of Both the Flag State and the Control of Ships by Port State Control. Beijing Law Rev. 2013; 04(04): 141-146, doi: 10.4236/blr.2013.44018.

66. European Parliament (2007). Employment Policy, Call For Speedy Ratification of Maritime Labour Convention. Retrieved June 15, 2007 from the World Wide. http://www.europarl.europa.eu/news/expert/briefing page/3713-071-03-11-\%0A20070228BRI03712-12-03-2007-2007/ default_p001c010_en.htm.

67. Fotteler ML, Jensen OC, Andrioti D. Seafarers' views on the impact of the Maritime Labour Convention 2006 on their living and working conditions: results from a pilot study. Int Marit Health. 2018; 69(4): 257 263, doi: 10.5603/IMH.2018.0041, indexed in Pubmed: 30589065.

68. Graham C. Representing Seafarers Health and Safety on Board Ships: The Limits of the Representing Seafarers Health and Safety on Board Ships: The Limits of the MLC. 2019 (August). 